\title{
The Detection of Intact Double-Stranded DNA by MALDI
}

\author{
Paolo Lecchi and Lewis K. Pannell \\ Laboratory of Analytical Chemistry, NIDDK, National Institutes of Health, Bethesda Maryland, USA
}

DNA fragments have been analyzed by matrix-assisted laser desorption ionization (MALDI) and electrospray mass spectrometry. In many cases, only the single-stranded oligonucleotides have been detected. Recently, spectra of intact double-stranded DNA have been obtained in both electrospray and massive cluster impact ionization. We show here the first MALDI spectra of intact double-stranded DNA (EcoR1 adaptor 12/16) that is clearly not due to nonspecific dimer formation. 6-Aza-2-thiothymine was used as the matrix in the presence of ammonium citrate. Via the same procedure but with other matrices commonly employed for oligonucleotide analysis, the intact DNA duplex was not detected. No sign of the homodimer of either of the single strands is observed. Although the spectrum also shows peaks attributable to each of the single strands, these are demonstrated to arise from the DNA solution and not the sample preparation or desorption process. (I Am Soc Mass Spectrom 1995, 6, 972-975)

$\mathrm{W}$ ith the surge of interest in the identification and analysis of DNA, the ability to study noncovalent interactions, such as exist between the strands of double-stranded DNA, is of prime importance to biomedical researchers and structural biologists. Soft ionization techniques such as matrix assisted laser desorption ionization (MALDI) and electrospray have been used before for the analysis of noncovalently bound complexes, and are therefore reasonable choices for the examination of DNA duplexes. Although there have been a number of reports in the literature on the analysis of oligonucleotides and DNA strands by MALDI [1-20], the spectra shown of intact double-stranded DNA are subject to criticism. In the first place, the term "double-stranded" applied to DNA denotes true complementary pairing, not just dimers of monomeric species. Second, in the spectra of a 1:1 mixture of two oligomers (A, B), detection of multiple dimer peaks (AA, AB, BB) clearly indicates nonspecific co-desorption of $A$ and $B$. We consider that many of the articles on this subject tend to obscure the point that this is not consistent with the ionization of a single $\mathrm{AB}$ species.

In a series of articles, a group at Oak Ridge National Laboratories has reported the analysis of oligonucleotides [4-6] and then double-stranded DNA [12-15] Although the latter articles refer to the running of double-stranded DNA on MALDI, none of the spectra show DNA "flying" as the duplex. Bai et al. [16] also ran a duplex DNA, and although the implication was

Address reprint requests and correspondence to Paolo Lecchi, Building 8, Room B2A23, NIDDK, NIH, Bethesda MD 20892-0805. that intact double-stranded DNA had been detected intact, it could be deduced that only monomer ions were involved. In a previous publication, we similarly observed that a 16-mer base pair oligomer ionized as two unpaired oligonucleotides [20]. However, because the melting temperature of this DNA strand was approximately $14{ }^{\circ} \mathrm{C}$ (calculations were made by using the OLIGO version IV primer analysis software from National Biosciences, Inc. (Plymouth, MN)), melting temperatures are quoted relevant to the concentration of salts present at sample preparation, and the sample was handled at room temperature, it was not surprising that the duplex was not observed. Although the "melting temperature" of DNA refers to that temperature at which the strands break apart in solution, the importance of this temperature when solvents are removed and the sample is on the target is not obvious. As a result, although the lack of intact DNA duplex reported in MALDI could arise during sample preparation because of the physical-chemical conditions used (e.g., source of sample, temperature, $\mathrm{pH}$, ionic strength, interaction with matrices or acetonitrilewater solvent), it also could arise from dissociation during the sample desorption and ionization process (e.g., local heating of the sample or dissociation at ionization due to excess energy in the molecules). It is hard to judge the meaning of "melting temperature" in this context. In conclusion, although there are several reports on the analysis of DNA via MALDI, only the spectra of single-stranded oligodeoxynucleotides have been observed.

In contrast to MALDI, DNA duplexes have been observed via electrospray [21, 22]. In a careful study, 
Ding and Anderegg [23] were able to distinguish homodimers from heterodimers of DNA fragments. With both 6-mer complementary and noncomplementary oligonucleotide pairs, only nonspecific noncovalent dimers were observed. Even d(TTTTTT) gave a similar dimer distribution. However, two octanucleotides $\left(T_{m}\right.$ $=7.4{ }^{\circ} \mathrm{C}$ ) showed a preference in the spectrum for heterodimer formation and this excess was attributed to DNA-duplex folding. Two complementary pentadecanucleotides $\left(T_{m}=39.1{ }^{\circ} \mathrm{C}\right)$ showed little formation of the homodimer and were detected as double-stranded DNA.

Recently a spectrum of a short piece of doublestranded DNA was obtained under massive cluster impact ionization [24]. Although the double-stranded peak was quite small in comparison to the peaks from the single strands, it could be identified positively by its mass because the strands were different lengths. When we consider that the melting temperature of the duplex was low $\left(<-100^{\circ} \mathrm{C}\right.$; calculations were made by using the OLIGO version IV primer analysis software from National Biosciences, Inc. (Plymouth, MN). Melting temperatures are quoted relevant to the concentration of salts present at sample preparation), the fact that intact DNA was detected at all is quite surprising. Unfortunately, an expansion of the homodimer region was not shown to totally preclude clustering as the source of the duplex peak.

In a previous publication, we reported a new protocol for the analysis of oligonucleotides by MALDI that employed 6-aza-2-thiothymine (ATT) as the matrix [20]. In attempts to develop a method for the detection of intact double-stranded DNA, we observed that the peak that corresponds to the oligonucleotide duplex is often observed when ATT is used as the matrix and care is taken to avoid acidic $\mathrm{pH}$ and elevated temperature during sample preparation. To clearly resolve the peak of the homodimer from that of the heterodimer, a DNA duplex (EcoR1 adaptor) composed of a 16-mer and complementary 12 -mer was chosen for this work.

\section{Experimental}

EcoR1 adaptor double-stranded $16 / 12$ as a frozen solution and nuclease S1 (from Aspergillus orizae) were purchased from Promega (Madison, WI). 6-Aza-2thiothymine (ATT), 2', 4',6'-trihydroxyacetophenone (THA), 3-hydroxypicolinic acid (HPA), and ammonium citrate were purchased from Aldrich Chemical Co. (Milwaukee, WI). Apomyoglobin (horse skeletal muscle) and insulin (bovine pancreas) were both of sequencing grade and were obtained from Sigma Chemical Co. (St. Louis, MO), All of the preceding materials were used without further purification.

The MALDI spectra were acquired on a Kratos MALDI-TOF III instrument (Columbia, MD) with the instrument operated in linear mode. The accelerating voltage was $-22 \mathrm{kV}$ and negative ion spectra were acquired.
EcoR 1 adaptor was stored at $-20{ }^{\circ} \mathrm{C}$ until used and then thawed in wet ice when needed for sample preparation. Subsequent freezings and thawings produced lower quantities of intact DNA in the spectra obtained. The adaptor $(0.5 \mu \mathrm{L}, 10 \mathrm{pmol} / \mu \mathrm{L})$ was mixed directly on the MALDI target slide with $1 \mu \mathrm{L}$ of the matrix solution [ATT, THA, or HPA dissolved in a $1: 1(\mathrm{v} / \mathrm{v})$ solution of acetonitrile and $20-\mathrm{mM}$ ammonium citrate] [20]. The sample was allowed to dry at $4{ }^{\circ} \mathrm{C}$ in a vacuum desiccator for $10 \mathrm{~min}$ and then were analyzed by MALDI. Fifty laser shots were obtained linearly from across the sample surface and then averaged. These were enough to produce a good signal to noise ratio. The instrument was calibrated by using external standards of bovine insulin (5732.0 MW) and horse apomyoglobin (16950.5 MW).

Digestion with nuclease $S 1[25,26]$ was performed at $20^{\circ} \mathrm{C}$ in ammonium citrate buffer $(25 \mu \mathrm{L}, 0.2 \mathrm{M}, \mathrm{pH}$ 5) that contained $1-\mathrm{mM}$ zinc acetate and $0.1 \mathrm{u} / \mu \mathrm{L}$ of nuclease enzyme. Three microliter of EcoR1 adaptor was added and the sample digestion followed over time. Aliquots were taken from the mixture and applied directly to the laser slide at $0,1,2,5$ and $15 \mathrm{~min}$.

\section{Results and Discussion}

The two strands of the EcoR1 adaptor are 16 and 12 bases long, respectively, as shown:

\section{5'-AATTCCGT TGCTGTCG-3' $4863.2 \mathrm{MW}$

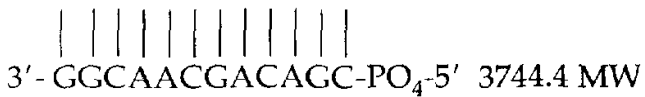

Neither $2^{\prime}, 4^{\prime}, 6^{\prime}$-trihydroxyacetophenone (Figure 1; inset) nor 3-hydroxypicolinic acid produced any peaks at the mass of the duplex when EcoR1 adaptor was analyzed. Instead the spectrum consisted of both the singly and doubly charged ions from the individual strands.

When 6-aza-2-thiothymine (ATT) was used as the matrix, the spectrum showed good intensity of the intact double-stranded DNA molecular ion peak at 8609.3 (see Figure 1; the molecular weight of the intact EcoR1 adaptor DNA [M $-\mathrm{H}^{-}$is 8606.6). Good resolution and accuracy were obtained (external standard, $0.03 \%)$ as reported for ATT [20]. Although some depurination was observed, this may have occurred during desorption or may have been present in the original sample. There was no sign of any homodimer $[2 \mathrm{M}-\mathrm{H}](\mathrm{m} / \mathrm{z} 7488,9725)$ being formed from the individual strands although peaks were present for each of the monomeric single strands $(m / z \quad 3743,4863)$. To resolve whether these were present in the original sample or arose during the desorption process, the results from each laser shot were profiled against the mass of the single strand and double-strand. Predominantly, the ions from the double-stranded DNA did not occur in individual laser pulses with the single- 
Figure 1. MALDI spectrum (50) lateer shots of EcoR1 12/16 adaptor with 6-aza-2-thiothymine (ATT) as the matrix. The DNA dimer region with $2^{\prime}, 4^{\prime}, 6^{\prime}$-trihydroxyacetophenone (THA) as the matrix is shown for comparison at a 20 times expansion in the inset. Only peaks from the singlestranded oligonucleotides were onserved with THA. The ion at 8609.3 (calc. 8606.6) in the ATT spectrum represents the detection of doublestranded DNA.

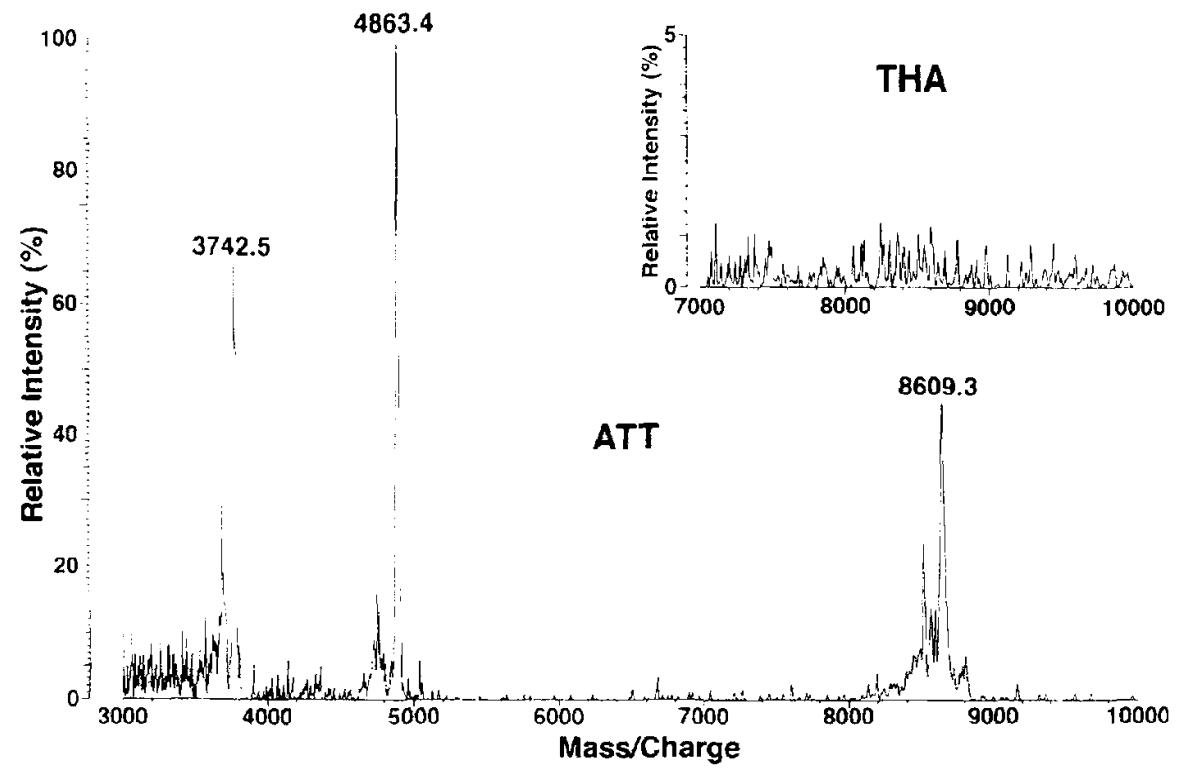

of the double-stranded DNA, these were shown to be present in the original sample of EcoR1 adaptor 12/16 by using an enzyme to preferentially digest the monomer.
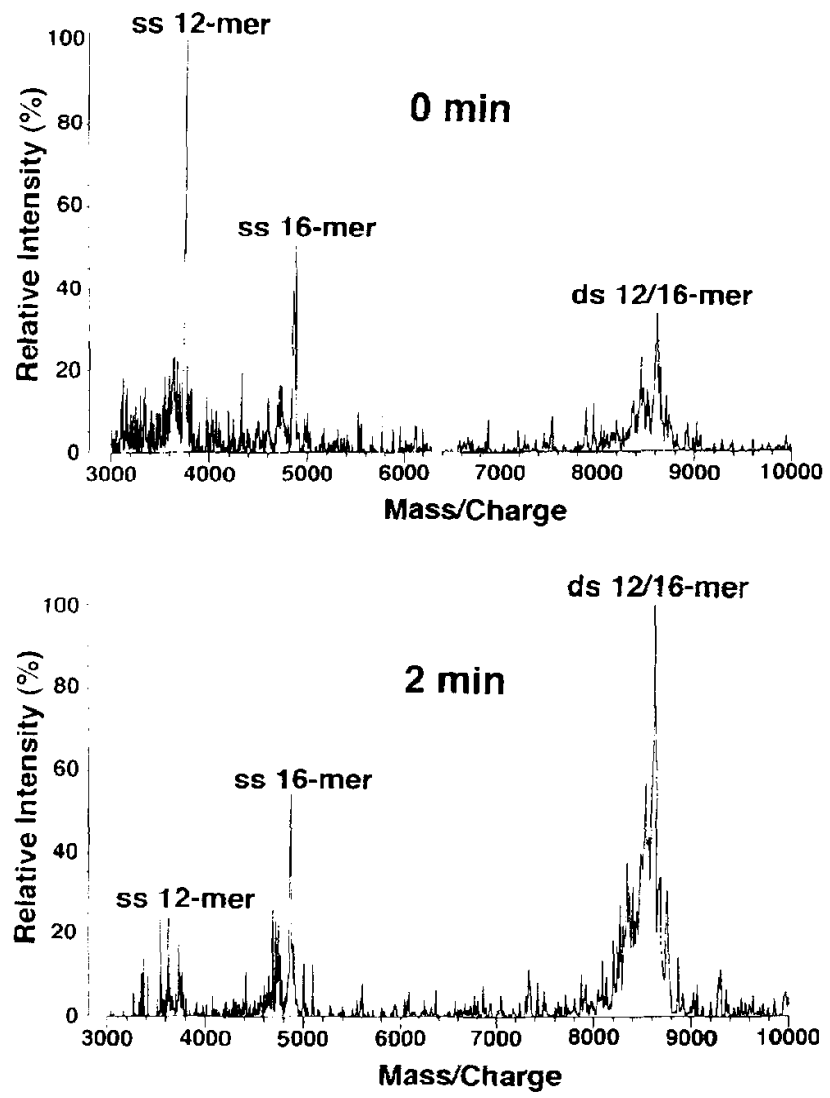

Figure 2. MALDI spectrum (50 laser shots) of EcoR1 12/16 adaptor (matrix azathiothymine) after digestion with nuclease $\$ 1$. An immediate withdrawal ( $(1 \mathrm{~min})$ of the sample shows little change from the original material (see Figure 1). After $2 \mathrm{~min}$, almost all of the single-stranded oligonucleotides had been digrested (Figure 2: $2 \mathrm{~min}$ ). 


\section{Acknowledgment}

We appreciate the use of the Kratos MALDI instrument housed in the Laboratory of Biophysical Chemistry, NHLBI (Dr. Henry Fales). Our thanks go to Dr. Alessandra Rovescalli, Laboratory of Biochemical Genetics, NHLBI, for helpful suggestions with regard to the experimental protocol.

\section{Note in Proof}

In a conference proceeding (p. 970, Abstracts of the $42^{\text {nd }}$ ASMS Conference on Mass Spectrometry and Allied Topics, Chicago, Illinois, 1994) $\mathrm{Wu}$ et al. reported the detection of double-stranded DNA, although they correctly point out that this could also be attributable to the single-stranded species.

\section{References}

1. Nordhoff, E.; Ingendoh, A.; Cramer, R.; Overberg, A.; Stahl, B.; Karas, M.; Hillenkamp, F.; Crain, P. F. Rapid Commun. Mass Spectrom. 1992, 6, 771-776.

2. Huth-Fehre, T.; Gosine, J. V.; Wu, K. J.; Becker, C. H. Rapid Commun. Mass Spectrom. 1992, 6, 204-213.

3. Wu, K. J.; Steding, A.; Becker, C. H. Rapret Commin. Muls Spectrom. 1993, 7, 142-146.

4. Tang, K.; Allman, S. L.; Iones, R. B.; Chen, C. H.; Araghi, S. Rapid Commun. Mass Spectrom. 1993, $7,435-439$.

5. Tang, K.; Allman, S. L.; Jones, R. B.; Chen, C. H.; Araghi, S Rapid Commum. Mers Spectrom. 1993, 7, 6.3-60.

6. Tang, K.; Allman, S. L.; Chen, C. H. Rilpid Commun. Mass Spectrom. 1993, 7. 943-948.

7. Curie, G. L.; Yates, J. R., lII 1. Ani. Six. Mass Spedrom 1993, 4 955-963

8. Schneider, K.; Chait, B. 1. (M.. Mass Sputrom. 1993, is $1353-1361$.
9. Pieles, U.; Zürcher, W.; Schär, M.; Moser, H. E. Nucleic Acids Res. 1993, 21, 3191-3196.

10. Fitzgerald, M. C.; Zhu, L.; Smith, L. M. Rapid Commun. Mass Spectrom. 1993, $7,895-897$.

11. Fitzgerald, M. C; Parr, G. R.; Smith, L. M. Anal. Chem. 1993, $65,3204-3211$.

12. Tang, K.; Allman, S. L.; Chen, C. H.; Ch'ang, L. Y.; Schell, M. Rapid Commun. Mass Spectrom. 1994, 8, 183-186.

13. Tang, K.; Taraneko, S. L.; Allman, S. L.; Chen, C. H.; Ch'ang, L. Y. Jacobson, K. B. Rapid Commun. Mass Spectromt. 1994, 8 , 673-677.

14. Tang, K.; Taranenko, N. L.; Allman, S. L.; Ch'ang, L. Y.; Chen, C. H. Rapid Commun. Mass Spectrom. 1994, 8, 727-730.

15. Taranenko, N. I, Tang, K.; Allman, S. L; Ch'ang; Chen, C. H. Rapid Conmun. Mass Spectrom. 1994, 8, 1001-1006.

16. Bai, J.; Liu, Y-H.; Lubman, D. M.; Siemieniak, D. Rapid Commun. Mass Spectrom. 1994, 8, 687-691.

17. Wang, B. H.; Biemann, K. Anal. Chem. 1994, 66, 1918-1924.

18. Williams, P. Int. I. Mass Spectrom. Ion Processes 1994, 131. $335-344$.

19. Nordhoff, E.; Karas, M.; Cramer, R.; Hahner, S.; Hillenkamp, F.; Kirpekar, F.; Lezius, A.; Muth, J.; Meier, C.; Engels, J. W. J. Mass Spectrom. 1995, 30, 99-112.

20. Lecchi, P.; Le, H. M. T.; Pannell, L. K. Nucleic Acids Res. 1995, 23, $1276-1277$.

21. Light-Wahl, K. J.; Springer, D. L.; Winger, B. E.; Edmonds, C. G.: Camp, D. G., II; Thrall, B. D.; Smith, R. D. J. Am. Chem. Soc. 1993, 115, 803-804.

22. Ganem, B.; Li, Y-T.; Henion, J. D. Tetrahedron Lett. 1993, 34, $1445 \cdots 1448$.

23. Ding. J.; Anderegg, R. J. 1. Am. Soc. Mass Spectront. 1995, 6, $159-164$.

24. Fabris, D.; Wu, Z.; Fenselau, C. C. I. Mass Spectrom. 1995, 1, $140 \cdots 143$.

25. Vogt, V. M. Eur. J. Biochem. 1973, 33, 192-198.

26. Williams, I. G.; Mason, P. I. Nucleic Acid Hybridization: A Practical Approncli: Hames, B. D.; Higgins, S. J., Eds.; IRL Press: Washington, DC, 1988, pp 139-160. 